\title{
ОРГАНИЗАЦИОННО-МЕТОДИЧЕСКИЕ АСПЕКТЫ ОБУЧЕНИЯ СТУДЕНТОВ-МЕДИКОВ ЗДОРОВОМУ ОБРАЗУ ЖИЗНИ
}

\author{
(C) Зорин К.В., Бурдюкова Е.В., Топорков В.А.
}

\author{
Кафедра ЮНЕСКО «Здоровый образ жизни - залог успешного развития» Московского \\ государственного медико-стоматологического университета имени А.И. Евдокимова, Москва \\ E-mail: zkv1000@yandex.ru
}

\begin{abstract}
Совершенствование системы высшего медицинского образования требует поиска новых методов учебной и воспитательной работы, направленных на пропаганду здорового образа жизни (ЗОЖ) и развивающих умение проводить культурно-просветительскую работу по первичной профилактике ряда социально значимых заболеваний. В статье анализируются организационно-методические особенности обучения будущих врачей ЗОЖ. Эти особенности определяют многие важные показатели для успешного формирования здоровьесберегающего мышления и поведения. Педагогические принципы формирования ЗОЖ близки принципам здоровьесберегающей педагогики. Для пропаганды ЗОЖ и проведения первичной профилактики заболеваний наиболее перспективны активные и групповые методы обучения. Методы данного исследования - ситуационный, логический, статистический.

Ключевые слова: высшее медицинское образование, организация здравоохранения, здоровый образ жизни, здоровьесберегающее поведение, первичная профилактика заболеваний.
\end{abstract}

\section{ORGANIZATIONAL AND METHODICAL ASPECTS OF TRAINING MEDICAL STUDENTS IN HEALTHY LIFESTYLE}

Zorin K.V., Burdukova E.V., Toporkov V.A.

UNESCO Department «Healthy lifestyle - the key to successful development»

of A.I. Evdokimov Moscow State University of Medicine and Dentistry, Moscow

The improvement of the higher medical education system requires searching for new methods of academic and educational work. These methods are aimed to encourage healthy lifestyle and develop skills of conducting cultural- educational work on primary prevention of some socially significant diseases. Organizational and methodical particularities of training in future healthy lifestyle have been analyzed in the article. These particularities determine many important factors for successful developing health-saving mentality and behavior. The teaching principles of developing healthy lifestyle are close to principles of health-saving pedagogical science. There is a need for active and group methods of teaching healthy lifestyle and conducting primary prevention of diseases. The methods of this study are situational, logical and statistical.

Keywords: higher medical education, organization of public health services, healthy lifestyle, health-saving behavior, primary prevention of diseases.

Актуальность обучения будущих врачей ЗОЖ определяется следующими обстоятельствами. Формально признавая полезность физической культуры, рационального питания и режима дня, пагубность абортов, сексуальной неразборчивости, переедания и прочих факторов риска, большинство студентов пренебрегает возможностью сохранить здоровье. При этом студенты осознают факторы риска как негативное явление, выделяя прежде всего злоупотребление алкоголем (75,6\%), курение $(73,5 \%)$ и недостаток двигательной активности $(39,9 \%)$ [1].

Молодые люди подвержены влиянию отрицательных социальных норм и традиций, не приучены к стилю мышления и поведения, обеспечивающему профилактику заболеваний. У нас плохо сформулирована, вернее утрачена идея здоровья как базовой национальной ценности, основы нравственного, социального и демографического благополучия общества. Здоровье людей, к сожа- лению, не является экономической и этической ценностью [2].

Поэтому государственная власть заявляет о необходимости усиления пропаганды здорового образа жизни. По итогам заседания президиума Совета при Президенте России по стратегическому развитию и приоритетным проектам 26 июля 2017 года утвержден паспорт приоритетного проекта «Формирование здорового образа жизни». Предполагается к концу 2019 года увеличить долю граждан, приверженных здоровому образу жизни, до 45\%, а к концу 2025 года - до 60\%; систематически занимающихся физической культурой и спортом - до $38 \%$ в 2019 и до $45 \%$ в 2025 годах. Поставлена задача снизить распространенность потребления табака среди взрослого населения с $30,5 \%$ в 2017 году до $29,5 \%$ в 2019 и $27 \%$ в 2025 годах, а также уменьшить потребление алкогольной продукции на душу населения с 10 литров в 2017 году до 9,3 литра в 2019 и 8 литров в 2025 годах [8]. 
Все вышеизложенное обусловливает и цель написания данной статьи - изучение организационно-методических аспектов обучения студентовмедиков ЗОЖ. Предмет исследования - особенности обучения будущих врачей ЗОЖ.

\section{МАТЕРИАЛЫ И МЕТОДЫ ИССЛЕДОВАНИЯ}

Совершенствование системы высшего медицинского образования требует поиска новых методов учебной и воспитательной работы, направленных на пропаганду ЗОЖ и развивающих умение проводить культурно-просветительскую работу по первичной профилактике ряда заболеваний. Совместно с другими кафедрами МГМСУ имени А.И. Евдокимова этим успешно занимается кафедра ЮНЕСКО «Здоровый образ жизни - залог успешного развития». Коллектив кафедры участвует и в совершенствовании гуманитарной подготовки будущих врачей, включая организационно-методические аспекты обучения ЗОЖ.

Так, практические и лекционные занятия соответствующего характера проводились со студентами стоматологического факультета в весенних семестрах 2016/2017 и 2017/2018 учебных годов, а со студентами лечебного факультета - в осеннем семестре 2017/2018 учебного года. Темы выбирались острые, вызывающие живой отклик и интерес, связанные, например, с профилактикой зависимого и рискованного поведения, ИППП, ВИЧ/СПИДа, искусственных абортов и осложнений контрацепции.

К организационно-методическим новациям в обучении ЗОЖ мы относим, к примеру, проблемную лекцию-беседу, лекцию с заранее запланированными ошибками и лекцию-визуализацию. Методы данного исследования - ситуационный, логический, статистический.

\section{РЕЗУЛЬТАТЫ ИССЛЕДОВАНИЯ И ИХ ОБСУЖДЕНИЕ}

Переход к личностно-ориентированной модели обучения повышает интерес к активным и групповым методам обучения (групповое решение задач, групповая дискуссия, деловые игры). Их мы и применяем на практических и лекционных занятиях по обучению ЗОЖ.

I. Групповое решение задач

Содержание учебной деятельности служит здесь средством общения, повышает мотивацию, облегчает раскрытие интеллектуальных и эмоциональных возможностей студентов. При этом развиваются ценностно-смысловое единство и творческий потенциал коллектива, клиническое мышление и активная жизненная позиция учащихся.
Вот пример ситуационной задачи лечебнодиагностического плана. Ученица 10 класса вместе с родителями собралась отдыхать в Индонезии. Нужно ли им делать профилактические прививки? Вопрос, поставленный перед студентами, можно развернуть: «Какова роль профилактических прививок в предотвращении инфекционных заболеваний?»; «Какие профессии требуют проведения дополнительной вакцинации?»; «Перед поездками в какие регионы земного шара и в какие сезоны года полезно проконсультироваться с инфекционистом-эпидемиологом?»

\section{II. Групповая дискуссия}

Организованное обсуждение каких-либо вопросов в учебной группе под руководством ведущего позволяет выявить мнения, идеи, переживания студентов и сопоставить их в непосредственном общении, лучше понять личностные и социально-психологические особенности каждого. Выработаны правила ведения дискуссии:

1. Направленность на разрешение проблемы, но не создание конфликта.

2. Не говорить долго, соблюдать регламент.

3. Выступать только по теме.

4. Стараться понять позицию оппонента.

5. Уметь выслушать до конца.

6. Не давать выход полемическому задору и помнить, что оппонент в дискуссии - не противник в жизни.

7. При несогласии с кем-либо не только сказать, что считаешь неправильным, но и предложить конструктивное решение.

Вот примерные темы групповых дискуссий: «Нравственные основы здорового образа жизни»; «Модели сексуального поведения и их роль в распространении ИППП и ВИЧ/СПИДа»; «Взаимосвязь употребления психоактивных веществ и подверженности инфекционным заболеваниям» и т.П.

Большое значение в деле пропаганды ЗОЖ и первичной профилактики заболеваний имеет понимание внутренней картины болезни, мотивов поведения и других психологических особенностей людей. Так, мы предлагаем студентам проанализировать поступки некоторых ВИЧинфицированных лиц. Они знают, что неизлечимо больны и заразны для окружающих. Но, несмотря на предупреждения врачей, вступают в новые сексуальные связи. Ими движет чувство озлобления, обида на судьбу, досада на себя. По откровенному признанию пациента, будучи «одной ногой в могиле», он скрыл свою болезнь от партнеров и злорадствовал, когда те стали его «друзьями по несчастью». Вот такая изощренная форма ВИЧ-терроризма - «кровавая» месть, точнее месть через кровь! Педагогу полезно приводить подобные случаи для совместного размыш- 
ления со студентами $[3,4]$.

III. Ситуационно-ролевые (деловые) игры

Суть метода состоит в импровизированном разыгрывании ситуации, моделирующей какуюлибо деятельность и возникающие в ходе нее проблемы. Несколько человек играют роли отдельных персонажей. Одна и та же ситуация может проигрываться несколько раз, чтобы дать возможность всем участникам побывать в разных ролях.

Существуют многочисленные модификации деловых игр с использованием различных методик. Их выбор определяется конкретными педагогическими задачами. Однако обязательное условие - проигрывание нескольких игр по нарастающей сложности, так как участие в одной игре обычно не дает желаемого эффекта. Моделируемая ситуация должна максимально приближаться к реальной. Важно, чтобы содержание ситуации было адекватно действительности и понятно каждому, а возникающие вопросы - значимы для участников.

По нашему мнению, необходимо выработать концепцию обучения здоровому образу жизни, которая отражала бы связь между житейским опытом, научными знаниями, мастерством преподавания и мировоззренческими ценностями. Цели и задачи воспитания здорового образа жизни, функции, содержание и критерии успешности такой воспитательной работы анализируют известные отечественные педагоги и методисты: Ю.К. Бабанский, Е.П. Бруновт, Н.М. Верзилин, И.Д. Зверев, В.В. Краевский, В.М. Кроль, Л.И. Маленкова, А.Н. Мягкова, П.И. Пидкасистый, В.А. Сластенин, И.Ф. Харламов, Н.К. Смирнов, А.М. Митяева и другие авторы.

Педагогические принципы формирования здорового образа жизни, на наш взгляд, близки принципам здоровьесберегающей педагогики [5, $6,7]$. Среди них особо выделим следующие:

1. Гиппократовский принцип ненанесения вреда проверен столетиями и в комментариях не нуждается.

2. Принцип представления о единстве физического, психического, социального и духовного здоровья, опирающийся на биопсихосоциодуховную модель человеческой личности и учитывающий биопсихосоциодуховную модель болезни.

3. Принцип приоритета действенной заботы о здоровье педагогов и обучающихся (школьников, студентов, слушателей и т.д.). Все происходящее в образовательном учреждении (разработка планов, проверка выполнения программ, проведение занятий, организация внеучебной деятельности, подготовка педагогических кадров и пр.) оценивается с позиций влияния на психофизиологическое состояние, профессиональное и духовное здоровье. Для этого требуется проводить посто- янный мониторинг.

4. Принцип непрерывности и преемственности: здоровьесберегающая работа ведется каждый день и на каждом занятии с обязательным учетом того, что уже было сделано ранее в рамках организационных и учебно-воспитательных мероприятий.

5. Принцип личностно-ориентированного взаимоотношения педагогов и обучающихся: вопросы здорового образа жизни включены в содержание учебных программ, обеспечен здоровьесберегающий характер и результат проведения процесса обучения.

6. Принцип соответствия содержания и организации образования возрастным особенностям обучающегося. Речь идет, например, о соответствии объема учебной нагрузки и уровня сложности изучаемого материала индивидуальным возможностям конкретного студента. Отсюда приоритет активных методов обучения и позитивных воздействий (подкреплений) над негативными (запретами, порицаниями).

7. Принцип сочетания охранительной и тренирующей стратегии призван создать щадящий, не утомляющий, а в идеале оптимальный уровень учебной нагрузки на основе индивидуального подхода к каждому обучающемуся.

8. Принцип формирования личной ответственности за собственное здоровье и мотивации к ведению здорового образа жизни. Наличие знаний о здоровье и способах его укрепления вовсе не гарантирует, что мы будем следовать им. Поэтому следует выработать и реализовать установку: здоровье есть важнейшая земная ценность. Так создается устойчивая здоровьесберегающая мотивация.

Приведенный перечень педагогических принципов формирования здорового образа жизни, конечно же, не исчерпывающий. Но он сразу обнажает ряд нерешенных вопросов, весьма актуальных в студенческой среде. Вот некоторые из них:

- как своевременно и эффективно снимать учебные перегрузки, приводящие к переутомлению нервной системы и психосоматическим отклонениям?

- $\quad$ как правильно организовать рациональное питание в вузе?

- как предотвратить вредное воздействие факторов, непосредственно связанных с образовательным процессом (профилактика гиподинамии, нарушений осанки, зрения и пр.)?

- как укреплять эмоциональную сферу личности (профилактика стрессов, вредных привычек, зависимостей от психоактивных веществ и состояний и т.д.)?

Таким образом, исследование организацион- 
но-методических аспектов обучения студентовмедиков ЗОЖ позволяет определить многие важные показатели для успешного формирования здоровьесберегающего мышления и поведения. Педагогические принципы формирования ЗОЖ близки принципам здоровьесберегающей педагогики и обусловливают особенности обучения ЗОЖ в системе высшего медицинского образования. Для пропаганды ЗОЖ и проведения первичной профилактики заболеваний наиболее перспективны активные и групповые методы обучения.

Работа выполнена в рамках гранта Президента Российской Федерации для государственной поддержки молодых российских ученых кандидатов наук (МК-2287.2017.7).

\section{ЛИТЕРАТУРА / REFERENCES}

1. Виленский М.Я., Гориков А.Г. Физическая культура и здоровый образ жизни студента: учебное издание. - 4-е изд., стер. - М. : КноРус, 2016. C. 130. [Vilenskiy M.Ya., Gorshkov A.G. Physical culture and healthy lifestyle of a student: educational publication. $4^{\text {th }}$ ed., stereotypical. - M. : KnoRus; 2016: 130 (in Russ.)].

2. Гуревич К.Г., Зорин К.В. Здоровьецентрическая медицина. Опыт кафедры ЮНЕСКО Московского государственного медико-стоматологического университета имени А.И. Евдокимова // Медицинская газета. - 2017. - № 86(7804). - С. 11. [Gurevich K.G., Zorin K.V. Healthycentric medicine. The experience of the UNESCO Chair of the Moscow State University of Medicine and Dentistry named after A.I. Evdokimova. Meditsinskaya gazeta. 2017; (86(7804)): 11 (in Russ.)].

3. Кудрявая Н.В., Зорин К.В. Духовно-нравственные и просветительские аспекты врачебной деятельности в области инфекционных болезней // Инфекционные болезни: новости, мнения, обучение. -
2015. - № 3(12). - C. 8-12. [Kudryavaya N.V., Zorin K.V. Spiritual, moral and educational aspects of medical practice in the field of infectious diseases. Infektsionnyye bolezni: novosti, mneniya, obucheniye. 2015; (3(12)): 8-12 (in Russ.)].

4. Кудрявая Н.В., Зорин К.В. Педагогические и ценностно-смысловые подходы к изучению инфекционных болезней: от истории к современности // Инфекционные болезни: новости, мнения, обучение. - 2015. - № 4 (13). - C. 20-24. [Kudryavaya N.V., Zorin K.V. Educational and axiological approaches to infectious diseases study: from history to modern times. Infektsionnyye bolezni: novosti, mneniya, obucheniye. 2015; (4(13)): 20-24 (in Russ.)].

5. Митяева A.M. Здоровьесберегающие педагогические технологии. Учебное пособие. - М. : Академия, 2010. - 192 с. [Mityayeva A.M. Health-saving pedagogical technologies. Tutorial. M. : Akademiya; 2010: 192 (in Russ.)].

6. Смирнов Н.К. Здоровьесберегающие технологии и психология здоровья в школе. - М.: АРКТИ, 2005. - 320 c. [Smirnov N.K. Health-saving technologies and health psychology at school. M. : ARKTI; 2005: 320 (in Russ.)].

7. Смирнов Н.К. Здоровьесберегающие образовательные технологии в современной школе. - М. : АРКТИ, 2008. - 288 с. [Smirnov N.K. Health-saving educational technologies in modern school. M. : ARKTI; 2008: 288 (in Russ.)].

8. Утвержден паспорт приоритетного проекта «Формирование здорового образа жизни» // Официальный сайт Правительства Российской Федерации. - - Режим доступа: http://www.government.ru/news/28745/, свободный (15.05.2018) [The passport of the priority project "Formation of a healthy lifestyle" was approved. Official site of the Government of the Russian Federation. Access mode: http://www.government.ru/news/28745/, free (05/15/2018) (in Russ.)]. 